\title{
Noise pollution has limited effects on nocturnal vigilance in peahens
}

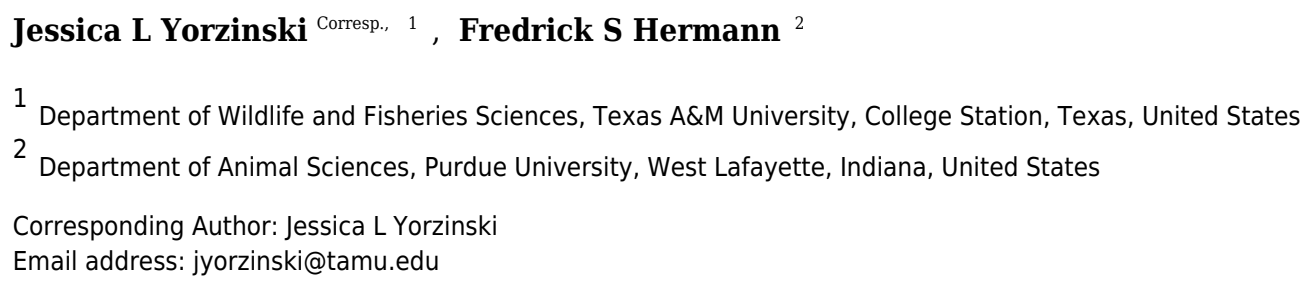

Natural environments are increasingly exposed to high levels of noise pollution. Noise pollution can alter the behavior of animals but we know little about its effects on antipredator behavior. We therefore investigated the impact of noise pollution on vigilance behavior and roost selection in an avian species, peafowl (Pavo cristatus), that inhabits urban environments. Captive peahens were exposed to noise pollution at night and their vigilance levels and roost selections were monitored. The vigilance levels of peahens were unaffected by exposure to noise pollution within trials. Furthermore, the peahens exhibited no preference for roosting farther or closer to noise pollution. Interestingly, predators often avoided the experimental area during nights with noise pollution, which could explain why vigilance rates were higher overall during control compared to noise trials. The results suggest that peahens' perception of risk is not drastically impacted by noise pollution but longer-term studies will be necessary to assess any chronic effects. 
$4 \quad{ }^{1}$ Department of Wildlife and Fisheries Sciences, Texas A\&M University, College Station, TX 
10 Natural environments are increasingly exposed to high levels of noise pollution. Noise pollution

11 can alter the behavior of animals but we know little about its effects on antipredator behavior. We

12 therefore investigated the impact of noise pollution on vigilance behavior and roost selection in

13 an avian species, peafowl (Pavo cristatus), that inhabits urban environments. Captive peahens

14 were exposed to noise pollution at night and their vigilance levels and roost selections were

15 monitored. The vigilance levels of peahens were unaffected by exposure to noise pollution within

16 trials. Furthermore, the peahens exhibited no preference for roosting farther or closer to noise

17 pollution. Interestingly, predators often avoided the experimental area during nights with noise

18 pollution, which could explain why vigilance rates were higher overall during control compared

19 to noise trials. The results suggest that peahens’ perception of risk is not drastically impacted by

20 noise pollution but longer-term studies will be necessary to assess any chronic effects.

\section{INTRODUCTION}

22 Noise pollution is increasingly prevalent in natural environments. Over $85 \%$ of the contiguous

23 United States is exposed to noise pollution (Mennitt et al., 2013). Noise pollution is usually

24 louder and more frequent than natural sounds in the environment and can therefore mask these

25 natural sounds (Kight \& Swaddle, 2011). In addition, noise pollution is often associated with 
26 other types of disturbances, such as light or chemical pollution (Halfwerk \& Slabbekoorn, 2015).

27 Because many animals use acoustic information to inform their behavioral decisions (Bradbury \&

28 Vehrencamp, 1998), noise pollution can have major impacts on their fitness (Patricelli \&

29 Blickley, 2006; Shannon et al., 2015).

30 Noise pollution could impact fitness because of its effect within a variety of different

31 contexts. It can affect the mating behavior of animals. Pair bonds in zebra finches (Taeniopygia

32 guttata) weaken when the birds are exposed to noise pollution (Swaddle \& Page, 2007) and male

33 sage grouse (Centrocercus urophasianus) attendance on breeding grounds decreases with noise

34 pollution (Blickley, Blackwood \& Patricelli, 2012). Noise pollution can impact territorial

35 behavior as well. Many passerines adjust their songs, which function in both territory defense and

36 mate attraction, to compensate for increased noise levels (Mockford \& Marshall, 2009). They

37 vocalize louder (Brumm 2004), repeat songs (Brumm \& Slater 2006), or sing during times of low

38 noise (Fuller, Warren \& Gaston, 2007). Noise pollution can also impact parental investment;

39 female house sparrows (Passer domesticus) provide less food to their young when living in noisy

40 environments (Schroeder et al., 2012).

41 Less is known about the effects of noise pollution on antipredator behavior (Meillère,

42 Brischoux \& Angelier, 2015). However, noise pollution has the potential to alter animals’

43 perception of the environment (Quinn et al., 2006; Shannon et al., 2014a). For example, animals

44 that are exposed to noise pollution may perceive the environment as more dangerous because

45 their ability to detect auditory signals and cues is low (Quinn et al., 2006). Chaffinches (Fringilla

46 coelebs) are more vigilant and peck less in response to noise pollution, suggesting that they

47 perceive their noisy environment as risky. In contrast, other animals’ perception of their

48 environment may not be impacted by noise pollution (Bejder et al., 2009). These animals could

49 have already habituated to the noise if they never experienced negative effects in noisy

50 environments or if they are generally tolerant of noise. For example, noise pollution does not 
51 impact gerbils’ (Gerbillus allenbyi and G. pyramidum) selection of a safe versus risky

52 microhabitat (Abramsky et al., 1996) and therefore does not seem to alter their perception of the

53 riskiness of their environment. Finally, some animals may perceive environments with noise

54 pollution as relatively safe because noise-sensitive predators may avoid these areas (Francis,

55 Ortega \& Cruz, 2009). Elk (Cervus elephus) are less vigilant in response to noise pollution

56 (Shannon, Cordes, Hardy, Angeloni, \& Crooks, 2014), suggesting that they view noisy

57 environments as less risky. While we are beginning to understand how species perceive noise

58 pollution with respect to risk levels during their active periods (daytime for diurnal species), we

59 are unaware of any studies that have investigated this topic during their inactive periods

60 (nighttime for diurnal species). Given that animals often rely on their senses differently

61 depending on whether it is daytime or nighttime (e.g., some birds use their visual capabilities to

62 forage during the day but switch to tactile capacities at night; Robert \& McNeil, 1988), animals’

63 responses to noise pollution could vary depending on this factor.

64 We therefore examined the impact of noise pollution on nocturnal vigilance and roosting 65 behavior in a diurnal avian species, peafowl (Pavo cristatus), that inhabits urban environments

66 (Ramesh \& McGowan, 2009). Peafowl are native to the Indian subcontinent and have also been

67 introduced to other continents (Kannan \& James, 1998). While they naturally live in deciduous

68 forests and scrubby woodlands, they also live near human settlements (Ali \& Ripley 1969;

69 Johnsingh \& Murali, 1978). They roost atop tall structures at night (such as trees; de Silva,

70 Santiapillai \& Dissanayake, 1996) and are subject to predation by mammalian and avian

71 predators (de Silva, Santiapillai \& Dissanayake, 1996; Kannan \& James, 1998). There are three

72 alternative explanations for how peafowl perceive noisy environments. First, if peafowl perceive

73 their environments as risky when there is noise pollution, then we expect them to exhibit high

74 rates of vigilance in response to noise pollution and avoid roosting in areas with high levels noise

75 pollution. Second, if peafowl are tolerant of noise pollution or have previously habituated to it, 
76 then we do not expect their vigilance rates to change from baseline levels and expect them to

77 select their roosts irrespective of noise pollution. And third, if peafowl perceive environments

78 with noise pollution as an escape from predators, then we expect their vigilance levels to decrease

79 in response to noise pollution and we expect them to roost near high levels of noise pollution. In

80 addition, because noise pollution can be stressful to some species and cause physiological

81 changes (Blickley et al., 2012), we examined whether the mass of peahens changed depending on

82 their exposure to noise pollution.

\section{METHODS}

84 We explored the effect of artificial noise pollution on vigilance levels and roost selection in 85 captive peahens at the Purdue Wildlife Area in West Lafayette, IN, USA $\left(40.450327^{\circ} \mathrm{N}\right.$, $\left.86-87.052574^{\circ} \mathrm{E}\right)$. The vigilance levels experiment was conducted between July 2014 and April

872015 and the roost experiment was conducted between March and June 2016. The experiments

88 were performed in an outdoor experimental cage $(4.5 \mathrm{~m} \mathrm{x} 9.0 \mathrm{~m})$ that was $75 \mathrm{~m}$ from the outdoor 89 aviary $(24.4 \times 18.3 \times 1.8 \mathrm{~m})$ where the birds were permanently housed (the distance between the 90 experimental cage and main aviary ensured that birds in the main aviary did not hear the

91 broadcast noise from the experimental cage). The aviary was over $550 \mathrm{~m}$ from the nearest major 92 road and it was surrounded by trees; noise pollution from anthropogenic sources was therefore

93 minimal. The peahens were adults and were given food and water ad libitum. The study was 94 approved by Purdue University Animal Care and Use Committee (\#1305000862 \& 1504001232 ).

\section{Vigilance Levels}

96 We tested whether artificial noise pollution impacts vigilance levels in peahens $(n=30)$. For each

97 trial, a peahen was put inside of the experimental cage for seven consecutive nights (the

98 experimental design was similar to Yorzinski et al., 2015). The experimental cage had one 
99 wooden roost (0.85 m tall and $1.3 \mathrm{~m}$ long) that was $1.5 \mathrm{~m}$ from a rock-shaped speaker (150 W

100 Outdoor Rock Speaker, model: tfs6sl, TIC Corporation, City of Industry, California, USA). The

101 speaker was connected to an audio amplifier (Audioengine N22, Austin, Texas) and an iPod touch

102 (model A1509, Apple Corporation, Cupertino, California, USA). During noise trials, the speaker

103 continuously broadcast white noise (white Gaussian noise generated with Matlab; 16 bit; 44.1

$104 \mathrm{~Hz}$ ) during nights (and days) 2-5; no noise was broadcast on nights 1, 6, or 7. The white noise

105 automatically turned on at noon on the second day and turned off at noon on the sixth day

106 (Woods outlet timer, model 50002, Mississauga, Canada). During medium noise trials ( $\mathrm{n}=10$ ), the

107 white noise had a sound pressure level (SPL) of $75 \mathrm{~dB}$ (A weighting; slow setting) at the middle

108 of the roost; during loud noise trials $(n=10)$, the white noise measured $90 \mathrm{~dB}$ SPL at the middle of

109 the roost (model 407730, Extech Instruments, Waltham, MA, USA). During control trials (n=10),

110 white noise was not broadcast on any of the seven nights. The medium and loud noise trials

111 broadcast noise at the same decibel levels as used in a previous study on noise pollution and birds

112 (Swaddle \& Page, 2007); noise pollution in urban environments can exceed the decibel level that

113 we broadcast in our loud noise trials (Chepesiuk, 2005). Furthermore, the peahens were not

114 necessarily exposed to the same level of noise pollution for the entire trial. During the day, they

115 could move to the opposite side of the experimental cage and therefore reduce the loudness of the

116 noise that they experienced. And, even though the peahens could have slept on the ground at the

117 opposite side of the speaker at night, they always slept on the roost near the speaker.

118 The head movements of the peahens were continuously monitored with a 3-axis

119 accelerometer (TechnoSmart, Rome, Italy; 3mm x 1.1 mm; 0.5 g; sample resolution:

$12019.6 \mathrm{~m} \mathrm{~s}^{-2}$; sample rate: $50 \mathrm{~Hz}$ ). The accelerometer was attached to a velcro strip (3.5 mm x 1.8

$121 \mathrm{~mm}$ ) that was glued (Artiglio Super 620) to the feathers atop the birds' head (see Yorzinski et al.,

1222015 for further details on accelerometer and attachment). The accelerometer was replaced every

123 day because the battery would not last for the duration of an entire trial. The accelerometer does 
124 not impact head movement rates (Yorzinski et al., 2015). We used a custom algorithm to extract

125 the number of head movements the peahens exhibited during each night of the trial (starting $1 \mathrm{~h}$

126 after sunset and ending $1 \mathrm{~h}$ before sunrise; "nighttime period”); the accuracy of this algorithm is

127 high (over 90\% of head movements are correctly classified as head movements; see Yorzinski et 128 al., 2015 for more details).

129 The peahens were weighed at the start and end of the trial (ZIEIS Veterinary Pet Scale,

130 Apple Valley, Minnesota; 5 g accuracy). The length of the peahens' tarsus + metatarsus was

131 measured at the start of the entire experiment (Neiko digital caliper; Neiko Tools, Wenzhou,

132 Zhejiang, China; model number: 01409 A; \pm 0.03 mm accuracy). Three video cameras (Swann

133 Pro-500, Swann Communications, Santa Fe Springs, California, USA) connected to a DVR

134 (Swann DVR4-2600) recorded the experimental cage and the area immediately outside the

135 experimental cage ( $2 \mathrm{~m}$ from the cage perimeter). Using these video recordings, we determined

136 the amount of time that predators (raccoons and domestic cats) and non-predators (mice, frogs,

137 flying squirrels, deer, and rabbits) were visible during the nighttime period. We also assessed the

138 time at which the peahens ascended to and descended from the roost each night. The time at

139 which a bird ascended to the roost for the night was assessed by moving backwards in the videos

140 from the nighttime period (1 h after sunset) and finding the time when the bird jumped on the

141 roost. If the bird was not already on the roost $1 \mathrm{~h}$ after sunset, then we moved forward in the

142 videos until the bird jumped on the roost. The time at which a bird descended from the roost for

143 the night was assessed in a similar way except that we moved forward in the videos from the

144 nighttime period ( $1 \mathrm{~h}$ before sunrise) until finding the time when the bird jumped off the roost. If

145 the bird was already off the roost 1 h before sunrise, we moved backward in the videos until the

146 bird jumped off the roost. We excluded times when the experimenters interfered with when the

147 bird ascended to the roost or descended from the roost. 


\section{Roost Selection}

149 In the first roost selection experiment, we tested whether peahens' $(n=20)$ selection of nocturnal 150 roosting locations was impacted by a medium-level of artificial noise pollution. For each trial, a

151 peahen was put inside of the experimental cage (at least $4.5 \mathrm{hr}$ before sunset) for one night. The

152 cage had two wooden roosts (0.85 $\mathrm{m}$ tall and $1.3 \mathrm{~m}$ long; $5.7 \mathrm{~m}$ between roosts) and a rock-

153 shaped speaker (150 W Outdoor Rock Speaker, model: tfs6sl, TIC Corporation, City of Industry,

154 California, USA) that was positioned in front of each roost (1.4 m between the speaker and

155 roost). One of the speakers (randomly selected for each trial) was connected to an audio amplifier

156 (Audioengine N22, Austin, Texas, USA) and an iPod touch (model A1509, Apple Corporation,

157 Cupertino, California, USA) that continuously broadcast white noise (white Gaussian noise

158 generated with Matlab; 16 bit; $44.1 \mathrm{~Hz}$ ). In the middle of the roost that was closer to the speaker,

159 the white noise measured $75 \mathrm{~dB}$ SPL; in the middle of the roost that was farther from the speaker,

160 the white noise measured $50 \mathrm{~dB}$ SPL (model 407730, Extech Instruments, Waltham, MA, USA).

161 Two video cameras (Swann Pro-500) connected to a DVR (Swann DVR4-2600) recorded the

162 experimental cage. Based on the video recordings, we determined whether the peahen slept on

163 the roost closer or farther from the noise.

164 In the second roost selection experiment, we tested whether peahens' $(n=20)$ selection of

165 nocturnal roosting locations was impacted by a high-level of artificial noise pollution. The

166 experimental procedure was the same as in the first roost selection experiment except the noise

167 level was increased. In the middle of the roost that was closer to the speaker, the white noise

168 measured $90 \mathrm{~dB}$ SPL; in the middle of the roost that was farther from the speaker, the white noise

169 measured 65 dB SPL (Extech Instruments; model 407730). Due to a limited number of peahens,

170 we tested 8 peahens that had not been used in the first roost selection experiment. In addition, we

171 randomly selected 12 birds that we used in the first roost selection experiment and used them in 
172 this second experiment as well (at least 33 days lapsed since a bird was used in the first roost

173 selection experiment; mean \pm SE: $61 \pm 6.1 \mathrm{~d})$.

174

175 Data analysis

176 We tested whether artificial noise pollution impacts nocturnal vigilance rates. We ran a repeated-

177 measures mixed linear model (PROC Mixed with a variance components covariance structure

178 and the between-within degrees of freedom approximation) to examine whether vigilance rates

179 differed among trials. The dependent variable was the natural log of the head movement rate

180 (number of head movements during nighttime period divided by the total time in the nighttime

181 period). The independent variables were the trial night (the specific night of the trial: $1-7)$, trial

182 type (control trial, medium noise trial, or loud noise trial), trial night by trial type interaction,

183 wind speed, precipitation, temperature, moon illumination, mass at the end of the trial, tarsus +

184 metatarsus, and predator and non-predator presence. We included environmental and

185 morphological variables within the model because these factors have been shown to impact

186 antipredator behavior (e.g., wind speed: Carr \& Lima, 2010; mass: Jones, Krebs, \& Whittingham,

187 2009). We performed a prior contrasts to compare specific trial nights.

188 The climate variables were obtained from a local weather station (http:

189 //iclimate.org; ACRE- West Lafayette). We calculated the mean of the wind speed (natural log

190 transformed) and temperature across the nighttime period. Since there was no precipitation during

$19182 \%$ of trial nights, precipitation was categorized as being present or absent. Moon illumination

192 was the fraction of the moon's surface that was illuminated from the sun's rays

193 (http://www.timeanddate.com; Lafayette, IN). Predator and non-predator presence was whether

194 predators or non-predators, respectively, were visible inside the cage or along the outside of the

195 cage perimeter or not during the nighttime period (predators and non-predators were visible in

196 only $50.8 \%$ and $68.5 \%$ of nights, respectively). We analyzed whether the amount of time that 
197 predators and non-predators spent near the experimental area (total time that predators or non-

198 predators were visible during the nighttime period divided by the nighttime period) was related to

199 trial type, trial night, trial type by trial night interaction, and environmental variables with a

200 repeated-measures mixed linear model. We performed $a$ prior contrasts to compare specific trial

201 nights. We also performed a mixed linear model to assess whether the mass of the birds changed

202 during the experiment; we calculated the percentage that the mass changed (mass on night 7

203 minus mass on night 1 divided by mass on night 1 ) and determined whether the trial type (control

204 trial, medium noise trial, or loud noise trial) impacted this percentage.

205 We ran another two repeated-measures mixed linear models to determine the factors

206 influencing when the birds ascended to the roost and descended from the roost for the night. The

207 independent variables were the trial type (control trial, medium noise trial, or loud noise trial),

208 trial night (the specific night of the trial: 1-7), trial type by trial night interaction, environmental

209 variables during the nighttime period (wind speed, precipitation, temperature, and moon

210 illumination), morphological measurements of the bird (mass and tarsus + metatarsus), and

211 predator and non-predator presence. We performed binomial tests (Proc Freq) to assess peahens’

212 roosting preferences (the peahens did not switch to a different roost during a given night). We

213 examined whether trial type (medium or loud noise), environmental variables (wind speed,

214 temperature, and moon illumination), and morphological variables impacted roost choice using a

215 binomial logistic regression (PROC Logistic). The wind speed and temperature at sunset during

216 the night of the trial were used in the analysis; precipitation at sunset during the night of the trial

217 was excluded from this analysis because precipitation was recorded in only $7.5 \%$ of trials.

218 Analyses were performed in SAS (9.3; Cary, NC, USA) or Minitab (15.1; Minitab Inc., State

219 College, PA, USA). The data supporting this article are available in Harvard Dataverse:

220 http://dx.doi.org/10.7910/DVN/FFEZQC. 


\section{RESULTS}

222 The head movement rate of peahens was similar regardless of trial night, the interaction between

223 trial type and trial night, environmental variables (wind, precipitation, temperature, and moon

224 illumination), morphological variables (mass and tarsus + metatarsus:), and predator presence

225 and non-predator presence. However, the head movement rate of peahens was lower during noise

226 trials compared to control trials (Table 1A). Comparing noise versus control trials on nights with

227 and without noise, the head movement rates were similar (Table 2A: Treatment effects). There

228 was a non-significant trend for head movement rate to be lower during nights with noise

229 compared to nights without noise, especially during medium noise trials. Within the noise trials,

230 the head movement rates were similar on nights with and without noise pollution; within the

231 control trials, the head movement rates were similar across nights (Table 2A: Time effects; Fig.

232 1). The results were qualitatively similar when the medium and noise trials were pooled. There

233 was no change in body mass within trials with respect to whether the birds were exposed to

234 artificial noise pollution or not $\left(\mathrm{F}_{2,24}=1.29, \mathrm{p}=0.29\right)$.

235 The amount of time that predators spent near the experimental area varied depending on

236 trial type, the interaction between trial type and trial night, wind speed, and temperature but not

237 trial night, precipitation, or moon illumination (Table 1B). Predators spent more time near the

238 experimental area during control versus noise trials (Fig. 2), when the wind speed was low, and

239 the temperature was high. They also spent more time near the experimental area during control

240 trials compared to noise trials during nights when the noise was broadcast in noise trials (Table

241 2B: Treatment effects). Within the noise trials and within the control trials, the amount of time

242 that predators spent near the experimental area did not vary (Table 2B: Time effects). The amount

243 of time that non-predators were near the experimental area was only impacted by the

244 temperature; the other variables were not significant (Table 1C). Non-predators spent more time

245 near the experimental area when the temperature was high. 
247 other independent variables did not affect when the birds ascended to the roost (Table 1D).

248 Peahens descended from the roost later in the morning during control trials compared to noise

249 trials (control: $24.3 \pm 7.8 \mathrm{~min}$ after sunrise; medium noise: $16.9 \pm 7.5 \mathrm{~min}$ after sunrise; loud

250 noise: $12.2 \pm 6.5$ min after sunrise) and when their tarsus + metatarsus was longer; the other

251 independent variables were not significant predictors of the time when the peahens descended

252 from the roost (Table 1E). Peahens did not exhibit a preference for roosting closer or further from

253 artificial noise (medium noise: $60 \%$ of the birds roosted away from the noise, $\mathrm{p}=0.50$; loud noise:

$25455 \%$ of the birds roosted away from the noise, $\mathrm{p}=0.82$; two-tailed binomial test). The type of

255 noise (medium or loud), wind speed, temperature, moon illumination, mass, and tarsus +

256 metatarsus did not impact whether the peahens roosted near or far from the noise (Table 1F).

\section{DISCUSSION}

258 The nocturnal vigilance levels of peahens were not significantly impacted by noise pollution

259 within trials. Individual peahens exhibited similar rates of head movements (a proxy of vigilance;

260 Jones, Krebs \& Whittingham, 2007) at night regardless of whether noise pollution was present or

261 absent. Furthermore, they showed no preference for roosting away from artificial noise pollution.

262 The results suggest that peahens' perception of risk is not drastically impacted by noise

263 pollution. They did not increase their vigilance behavior to compensate for a potentially reduced

264 ability to detect threats nor did they decrease their vigilance levels to take advantage of a

265 potentially safer environment within trials. In most of the studies examining vigilance behavior

266 and noise pollution, individuals elevate their vigilance levels in response to noise pollution

267 (however, these studies were conducted on diurnal species during the day while this study was

268 conducted at night; reviewed in Beauchamp, 2015): California ground squirrels

269 (Otospermophilus beecheyi) are more vigilant in areas with turbine noise (Rabin, Coss \& 
270 Owings, 2006), great tits (Parus major) are more vigilant when exposed to aircraft noise (Klett-

271 Mindo, Pavón \& Gil, 2016), prairie dogs (Cynomys ludovicianus) and white-crowned sparrows

272 (Zonotrichia leucophrys) are more vigilant in response to traffic noise (Shannon et al., 2014a;

273 Ware et al., 2015), chaffinches are more vigilant in response to white noise (Quinn et al., 2006),

274 and koalas (Phascolarctos cinereus) are more vigilant when hearing zoo visitors (Larsen Sherwen

275 \& Rault, 2014). This increased level of vigilance may allow animals to detect threats faster

276 (Meillère, Brischoux \& Angelier, 2015). However, some species may decrease their vigilance

277 levels in response to noise pollution because their risk perception is lower. Elk are less vigilant in

278 response to traffic noise (though human activity may have also contributed to this effect; Shannon

279 et al., 2014b).

280 In addition, noise pollution did not influence the peahens' selection of nocturnal roosting

281 locations. The peahens selected roosts irrespective of noise pollution levels, indicating that they

282 did not perceive noise pollution as impacting their risk. Because both roosts were exposed to

283 some level of noise pollution, it is possible that the peahens did not distinguish between them

284 since they were both noisy. Additional experiments in which one of the roosts is completely free

285 of noise would be important. Previous studies have found that some species avoid areas with

286 noise pollution (Blickley, Blackwood \& Patricelli, 2012; Ware et al., 2015) while other species do

287 not (Neo et al., 2015); an understanding of ecological differences between species could elucidate

288 why they respond differentially.

289 Even though we did not find that vigilance levels differed within trials, we did find that

290 peahens were more vigilant overall during control compared to noise trials. And, peahens

291 descended from the roost later in the morning overall during control trials compared to noise

292 trials. These overall effects could be related to predators being more frequent during control trials

293 (see below) and peahens adjusting to this increase in predator presence throughout the trial (i.e.,

294 carry-over effects). In fact, head movement rates across all nights during control trials in this 
295 study (171 \pm 9.9) were higher than control trials from a previous study conducted under similar

296 experimental conditions (99 \pm 6.5 ; Yorzinski et al., 2015); this suggests that changes in the

297 external environment, such as increased predators, may have resulted in the higher vigilance rates

298 during our control trials in this study. Because predator presence can impact vigilance behavior,

299 future experiments could be conducted in which predator presence is controlled. Additional

300 experiments will also be necessary to determine whether long-term effects of noise pollution

301 impact vigilance behavior.

302 Peahens may not rely strongly on acoustic cues when detecting nocturnal predators,

303 potentially explaining why they do not alter their perception of risk based on noise pollution

304 within trials. Nocturnal vigilance levels in peahens dramatically increases with exposure to

305 artificial light pollution (Yorzinski et al., 2015), suggesting that the birds heavily rely on vision to

306 detect predators. Given that peahens in the wild roost atop tall trees, they also likely rely on

307 vibrations to detect the approach of large predators. Noise pollution may mask acoustic cues from

308 predators but be less important than visual or vibrational cues to the peahens. Given that their

309 antipredator vocalizations are loud and cover a wide frequency range (Yorzinski, 2014), peahens

310 may also be able to hear conspecific warning calls despite noise pollution (Francis, 2015;

311 Pettinga, Kennedy \& Proppe, 2016). Additional studies that examine whether peahens use

312 acoustic cues during predator detection in the daytime would be useful. A comparative study

313 examining variation in species' response to noise pollution would help elucidate the factors

314 impacting the perception of risk in response to noise pollution across species.

315 It is possible that the peahens in this study had previously habituated to noise pollution.

316 The peahens were captured from feral populations located in country areas or suburban

317 neighborhoods at least two years prior to the onset of this study. They may therefore have

318 habituated to noise pollution while they were feral. However, the loudness and duration of the

319 noise pollution they experienced while they were feral were likely less than the loud noise 
320 treatment in this study. It is also possible that the birds habituated to the noise during the trials

321 because the noise was broadcast for four consecutive days. However, their nocturnal vigilance

322 levels were similar on the first and last day when the noise was broadcast, suggesting that

323 habituation within trials was not influencing vigilance rates.

324 Because nocturnal vigilance is inversely correlated with sleep in peahens (Yorzinski et al., 325 2015), noise pollution did not likely impact the amount of time the birds spent sleeping within 326 trials. In addition, they ascended the roost in the evening and descended from the roost in the 327 morning at similar times regardless of whether noise pollution was present or not within trials.

328 However, noise pollution could have affected their sleep patterns in subtler ways. In humans, 329 noise pollution can alter the amount of time spent in different stages of sleep (Pirrera, De Valck \& 330 Cluydts, 2010). Further research investigating the impact of noise pollution on sleep in birds 331 would be useful. One study found that European robins (Erithacus rubecula) sing at night when 332 they are exposed to noise pollution but how this behavioral change impacted their sleep behavior 333 was not explored (Fuller, Warren \& Gaston, 2007).

334 In our study, predators often avoided the experimental area during nights with noise 335 pollution. Similarly, Francis, Ortega \& Cruz (2009) found that avian predators avoided 336 depredating nests in areas exposed to noise pollution. In addition, three-spined sticklebacks 337 (Gasterosteus aculeatus) and greater mouse-eared bats (Myotis myotis) are less efficient hunters 338 when subjected to noise pollution (Purser \& Radford, 2011; Siemers \& Schaub, 2011). Because 339 some predators may be sensitive to noise pollution, prey may be safer and have higher 340 reproductive success in noisy environments (Francis, Ortega \& Cruz, 2009). However, in other 341 species, prey are more easily captured by predators when exposed to noise (Simpson, Purser \& 342 Radford, 2015; Simpson et al., 2016). The mechanisms underlying differences in hunting 343 behavior across species in response to noise are not well understood. 
345 accompany sources of noise pollution (Halfwerk \& Slabbekoorn, 2015). Understanding how

346 different types of disturbances singly and jointly influence antipredator behavior would be

347 informative. While we found that noise pollution had limited effects on nocturnal vigilance rates

348 in peahens in this study, we previously found that light pollution significantly increases their

349 nocturnal vigilance rates (similar sample size as used in this study; Yorzinski et al., 2015). Across

350 nights with exposure to pollution, nocturnal vigilance rates in response to noise pollution in this

351 study (medium noise: $118 \pm 3.5$; loud noise: $112 \pm 6.0$ ) were two times lower compared to

352 vigilance rates in response to light pollution in a similar study (246 \pm 38.6 ; Yorzinski et al.,

353 2015). Based on the evidence thus far, management practices aimed at minimizing artificial

354 disturbances to peafowl might therefore invest more in reducing light pollution compared to noise 355 pollution.

\section{ACKNOWLEDGEMENTS}

357 We thank the Purdue Department of Forestry and Natural Resources for allowing us to house the

358 birds on their property and providing logistical support. Jacie Anderson, Sarah Bischoff, Sydney

359 Byerley, Jeanne Coy, Bridget Craft, Connor Egyhazi, Sara Green, Amanda Gnerlich, Diamond

360 Jones, and Rachel Schultz helped performed the trials. Rebecca Budd, Bess Fary, Elissa Hall,

361 Donica Owsley, and Brooke Staley analyzed some of the video recordings.

\section{REFERENCES}

363 Ali S, Ripley SD. 1969. Handbook of the Birds of India and Pakistan, Vol. 2 (Oxford University

$364 \quad$ Press, Bombay), pp. 1-147. 
365 Abramsky Z, Strauss E, Subach A, Kotler BP, Riechman A. 1996. The effect of barn owls

366 (Tyto alba) on the activity and microhabitat selection of Gerbillus allenbyi and G.

367 pyramidum. Oecologia 105:313-319.

368 Bejder L, Samuels A, Whitehead H, Finn H, Allen S. 2009. Impact assessment research: use 369 and misuse of habituation, sensitisation and tolerance in describing wildlife responses to $370 \quad$ anthropogenic stimuli. Marine Ecology Progress Series 395:177-185.

371 Beauchamp G. 2015. Animal vigilance: Monitoring predators and competitors (Academic $372 \quad$ Press, Oxford).

373 Blickley JL, Blackwood D, Patricelli GL. 2012. Experimental evidence for the effects of 374 chronic anthropogenic noise on abundance of greater sage-grouse at leks. Conservation $375 \quad$ Biology 26:461e471.

376 Blickley JL, Word KR, Krakauer AH, Phillips JL, Sells SN, Taff CC, Wingfield JC,

377 Patricelli GL. 2012. Experimental chronic noise is related to elevated fecal corticosteroid 378 metabolites in lekking male greater sage-grouse (Centrocercus urophasianus). PLoS ONE 7(11):e50462.

380 Bradbury JW, Vehrencamp SL. 1998. Principles of animal communication. Sinauer Associates, Sunderland, MA.

Brumm H. 2004. The impact of environmental noise on song amplitude in a territorial bird.

Brumm H, Slater PJB. 2006. Ambient noise, motor fatigue, and serial redundancy in chaffinch Journal of Animal Ecology 73:434-440. song. Behavioral Ecology and Sociobiology 60:475-481.

Carr JM, Lima SL. 2010. High wind speeds decrease the responsiveness of birds to potentially threatening moving stimuli. Animal Behaviour 80(2):215-220.

Chepesiuk R. 2005. Decibel hell: The effects of living in a noisy world. Environmental Health Perspectives 113(1):A34-A41. 
390 de Silva PK, Santiapillai C, Dissanayake S. 1996. Some aspects of the population ecology of 391 the blue peafowl, Pavo cristatus, in Ruhuna National Park, Sri Lanka. Journal of South $392 \quad$ Asian Natural History 2:113-126.

393 Francis CD, Ortega CP, Cruz A. 2009. Noise pollution changes avian communities and species 394 interactions. Current Biology 19:1415-1419.

395 Francis CD. 2015. Vocal traits and diet explain avian sensitivities to anthropogenic noise. 396 Global Change Biology 21:1809-1820.

397 Fuller RA, Warren PH, Gaston KJ. 2007. Daytime noise predicts nocturnal singing in urban 398 robins. Biology Letters 3:368-370.

399 Halfwerk W, Slabbekoorn H. 2015. Pollution going multimodal: the complex impact of the 400 401 human-altered sensory environment on animal perception and performance. Biology

402 Letters 11: 20141051.

Johnsingh AJT, Murali S. 1978. The ecology and behaviour of the Indian peafowl (Pavo 403 cristatus) Linn. of Injar. Journal of the Bombay Natural History Society 75:1069-1079.

Jones KA, Krebs JR, Whittingham MJ. 2007. Vigilance in the third dimension: head movement not scan duration varies in response to different predator models. Animal Behavior 74:1181-1187.

Jones KA, Krebs JR, Whittingham MJ. 2009. Heavier birds react faster to predators: Individual differences in the detection of stalking and ambush predators. Behavioral Ecology and Sociobiology 63(9):1319-1329.

410 Kannan R, James DA. 1998. Common peafowl (Pavo cristatus). In: Polle A, Gill F, eds. The 411 birds of North America, vol. 377. Philadelphia. Available at 412 http://bna.birds.cornell.edu/bna/species/377.

413 Kight CR, Swaddle JP. 2011. How and why environmental noise impacts animals: an 414 integrative, mechanistic review. Ecology Letters 14:1052-1061. 
415 Klett-Mindo JI, Pavón I, Gil D. 2016. Great tits, Parus major, increase vigilance time and

416 reduce feeding effort during peaks of aircraft noise. Animal Behaviour 115:29-34.

417 Larsen MJ, Sherwen SL, Rault J.-L. 2014. Number of nearby visitors and noise

418 level affect vigilance in captive koalas. Applied Animal Behaviour Science 154:76e82.

419 Meillère A, Brischoux F, Angelier F. 2015. Impact of chronic noise exposure on antipredator

420 behavior: an experiment in breeding house sparrows. Behavioral Ecology 26:569-577.

421 Mennitt D, Fristrup KM, Sherrill K, Nelson L. 2013. Mapping sound pressure levels

422 on continental scales using a geospatial sound model. In: Proceedings of Inter-Noise, pp.

423 1-11. Innsbruck, Austria.

424 Mockford EJ, Marshall RC. 2009. Effects of urban noise on song and response behaviour in

425 great tits. Proceedings of the Royal Society Series B Biological Sciences 276:2979-2985.

426 Neo YY, Parie L, Bakker F, Snelderwaard P, Tudorache C, Schaaf M, Slabbekoorn H.

427 2015. Behavioral changes in response to sound exposure and no spatial

428 avoidance of noisy conditions in captive zebrafish. Frontiers in Behavioral

$429 \quad$ Neuroscience 9:1-11.

430 Patricelli GL, Blickley JL. 2006. Overview: Avian communication in urban

431 noise: the causes and consequences of vocal adjustment. The Auk 123: 639-649.

432 Pettinga D, Kennedy J, Proppe DS. 2016. Common urban birds continue to perceive predator 433 calls that overlapped by road noise. Urban Ecosystem 19:373-382.

434 Pirrera S, De Valck E, Cluydts R. 2010. Nocturnal road traffic noise: A review on its 435 assessment and consequences on sleep and health. Environmental International 36:492436498.

437 Purser J, Radford AN. 2011. Acoustic noise induces attention shifts and reduces foraging 438 performance in three-spined sticklebacks (Gasterosteus aculeatus). PLoS ONE 6:e17478.

439 Quinn JL, Whittingham MJ, Butler SJ, Cresswell W. 2006. Noise, predation risk 

Biology 37:601-608.

442 Rabin LA, Coss RG, Owings DH. 2006. The effects of wind turbines on antipredator behavior

443 in California ground squirrels (Spermophilus beecheyi). Biological Conservation

$444 \quad$ 131:410-420.

445 Ramesh K, McGowan P. 2009. On the current status of Indian peafowl Pavo cristatus

446 (Aves:Galliformes: Phasianidae): keeping the common species common. Journal of 447 Threatened Taxa 1:106-108.

448 Robert M, McNeil R. 1988. Comparative day and night feeding strategies of shorebird 449 species in a tropical environment. Ibis 131:69-79.

450 Schroeder J, Nakagawa S, Cleasby IR, Burke T. 2012. Passerine birds breeding under chronic $451 \quad$ noise experience reduced fitness. Plos One 7(7):8.

452 Shannon G, Angeloni LM, Wittemyer G, Fristrup KM, Crooks KR. 2014a. Road traffic 453 noise modifies behaviour of a keystone species. Animal Behaviour 94:135-141.

454 Shannon G, Cordes LS, Hardy AR, Angeloni LM, Crooks KR. 2014b. Behavioral responses 455 associated with a human-mediated predator shelter. PLoS ONE 9(4): e94630.

456 Shannon G, McKenna MF, Angeloni LM, Crooks KR, Fristrup KM, Brown E, Warner 457 KA, Nelson MD, White C, Briggs J, McFarland S, Wittemyer G. 2015. A synthesis of 458 two decades of research documenting the effects of noise on wildlife. Biological Reviews

459 Siemers BM, Schaub A. 2011. Hunting at the highway: traffic noise reduces foraging 460 efficiency in acoustic predators. Proceedings of the Royal Society Series B Biological 461 Sciences 278: 1646-1652.

462 Simpson SD, Purser J, Radford AN. 2015. Anthropogenic noise compromises antipredator 463 behaviour in European eels. Global Change Biology 21:586-593.

464 Simpson SD, Radford AN, Nedelec SL, Ferrari MCO, Chivers DP, McCormick MI, 
Meekan MG. 2015. Anthropogenic noise increases fish mortality by predation. Nature Communications 7:1-7.

467 Swaddle JP, Page LC. 2007. High levels of environmental noise erode pair preferences in zebra 468 finches: implications for noise pollution. Animal Behaviour 74:363-368.

469 Ware HE, McClure CJW, Carlisle JD, Barber JR. 2015. A phantom road experiment reveals traffic noise is an invisible source of habitat degradation. Proceedings of the National Academy of Sciences 112:12105-12109.

472 Yorzinski JL. 2014. Peafowl antipredator calls encode information about signalers. Journal of 473 the Acoustical Society of America 135:942-952.

474 Yorzinski JL, Chisholm S, Byerley S, Coy JR, Aziz AB, Wolf JA, Gnerlich A. 2015.

$475 \quad$ Artificial light pollution increases nocturnal vigilance in peahens. PeerJ 3: e1174. 
476 Figure 1. Head movement rates (means \pm SE) of peahens during noise (medium and loud) and 477 control trials.

478 Figure 2. Amount of time that predators were present (means \pm SE) during noise (medium and 479 loud) and control trials. 
480 Table 1. The impact of trial type, trial night, environmental and morphological variables, and

481 predator and non-predator presence on head movement rate, the amount of time predators and 482 non-predators spent near the experimental area, the times at which the birds ascended to and

483 descended from the roost, and roost selection. F values (numerator degrees of freedom,

484 denominator degrees of freedom) are displayed along with p-values for A-E; chi-square values 485 (degrees of freedom) are displayed along with p-values for F.

\begin{tabular}{|c|c|c|c|c|c|c|}
\hline & $\begin{array}{c}\text { A: Head } \\
\text { Movement } \\
\text { Rate }\end{array}$ & $\begin{array}{c}\text { B: } \\
\text { Predators }\end{array}$ & $\begin{array}{l}\text { C: Non- } \\
\text { predators }\end{array}$ & $\begin{array}{c}\text { D: } \\
\text { Ascend } \\
\text { Roost }\end{array}$ & $\begin{array}{c}\text { E: } \\
\text { Descend } \\
\text { Roost }\end{array}$ & $\begin{array}{l}\text { F: Roost } \\
\text { Selection }\end{array}$ \\
\hline Trial Type & $\begin{array}{c}3.57(2,25) \\
\mathbf{0 . 0 4 3}\end{array}$ & $\begin{array}{r}5.80 \\
(2,27) \\
\mathbf{0 . 0 0 8} \\
\end{array}$ & $\begin{array}{c}0.52 \\
(2,27) \\
0.60 \\
\end{array}$ & $\begin{array}{c}0.33 \\
(2,25) \\
0.72\end{array}$ & $\begin{array}{c}6.48 \\
(2,25) \\
\mathbf{0 . 0 0 5 4}\end{array}$ & 0.24 \\
\hline Trial Night & $\begin{array}{c}0.55(6,108) \\
0.77\end{array}$ & $\begin{array}{c}0.87 \\
(6,138) \\
0.52\end{array}$ & $\begin{array}{c}1.85 \\
(6,138) \\
0.095\end{array}$ & $\begin{array}{c}0.43 \\
(6,123) \\
0.86\end{array}$ & $\begin{array}{c}0.57 \\
(6,121) \\
0.75\end{array}$ & - \\
\hline $\begin{array}{l}\text { Trial Type * } \\
\text { Trial Night }\end{array}$ & $\begin{array}{c}0.24 \\
(12,108) \\
0.99 \\
\end{array}$ & $\begin{array}{c}2.58 \\
(12,138) \\
\mathbf{0 . 0 0 4 1}\end{array}$ & $\begin{array}{c}0.43 \\
(12,138) \\
0.95\end{array}$ & $\begin{array}{c}0.50 \\
(12,123) \\
0.91\end{array}$ & $\begin{array}{c}0.97 \\
(12,121) \\
0.48\end{array}$ & - \\
\hline Wind & $\begin{array}{c}0.03(1,108) \\
0.85\end{array}$ & $\begin{array}{c}7.21 \\
(1,138) \\
\mathbf{0 . 0 0 8 1}\end{array}$ & $\begin{array}{c}1.11 \\
(1,138) \\
0.29 \\
\end{array}$ & $\begin{array}{c}0.24 \\
(1,123) \\
0.62 \\
\end{array}$ & $\begin{array}{c}3.11 \\
(1,121) \\
0.081 \\
\end{array}$ & $\begin{array}{c}0.40(1) \\
0.53\end{array}$ \\
\hline Precipitation & $\begin{array}{c}0.77(1,17) \\
0.39\end{array}$ & $\begin{array}{c}0.15 \\
(1,19) \\
0.70\end{array}$ & $\begin{array}{c}1.08 \\
(1,19) \\
0.31\end{array}$ & $\begin{array}{c}0.06 \\
(1,18) \\
0.81\end{array}$ & $\begin{array}{l}2.14 \\
(1,18) \\
0.16\end{array}$ & - \\
\hline Temperature & $\begin{array}{c}3.04(1,108) \\
0.084\end{array}$ & $\begin{array}{r}15.49 \\
(1,138) \\
\mathbf{0 . 0 0 0 1} \\
\end{array}$ & $\begin{array}{c}5.74 \\
(1,138) \\
\mathbf{0 . 0 1 8} \\
\end{array}$ & $\begin{array}{c}24.06 \\
(1,123) \\
<\mathbf{0 . 0 0 0 1} \\
\end{array}$ & $\begin{array}{c}0.79 \\
(1,121) \\
0.38 \\
\end{array}$ & $\begin{array}{c}1.37(1) \\
0.24\end{array}$ \\
\hline Moon & $0.23(1,108)$ & 1.31 & 0.04 & 0.53 & 2.09 & $0.12(1)$ \\
\hline
\end{tabular}




\begin{tabular}{|c|c|c|c|c|c|c|}
\hline illumination & 0.63 & $\begin{array}{c}(1,138) \\
0.25\end{array}$ & $\begin{array}{c}(1,138) \\
0.85\end{array}$ & $\begin{array}{c}(1,123) \\
0.47\end{array}$ & $\begin{array}{c}(1,121) \\
0.15\end{array}$ & 0.73 \\
\hline Mass & $\begin{array}{c}1.16(1,25) \\
0.29\end{array}$ & - & - & $\begin{array}{c}0.35 \\
(1,25) \\
0.56 \\
\end{array}$ & $\begin{array}{r}3.09 \\
(1,25) \\
0.091 \\
\end{array}$ & $\begin{array}{c}1.17(1) \\
0.28\end{array}$ \\
\hline $\begin{array}{l}\text { Tarsus + } \\
\text { Metatarsus }\end{array}$ & $\begin{array}{c}3.42(1,25) \\
0.076\end{array}$ & - & - & $\begin{array}{c}2.80 \\
(1,25) \\
0.11 \\
\end{array}$ & $\begin{array}{r}12.15 \\
(1,25) \\
\mathbf{0 . 0 0 1 8} \\
\end{array}$ & $\begin{array}{c}0.089(1) \\
0.77\end{array}$ \\
\hline $\begin{array}{l}\text { Predator } \\
\text { Presence }\end{array}$ & $\begin{array}{c}0.39(1,23) \\
0.54\end{array}$ & - & - & $\begin{array}{c}0.82 \\
(1,22) \\
0.37\end{array}$ & $\begin{array}{c}1.89 \\
(1,23) \\
0.18\end{array}$ & - \\
\hline $\begin{array}{l}\text { Non-predator } \\
\text { Presence }\end{array}$ & $\begin{array}{c}0.34(1,14) \\
0.57\end{array}$ & - & - & $\begin{array}{c}0.15 \\
(1,15) \\
0.70 \\
\end{array}$ & $\begin{array}{c}0.15 \\
(1,14) \\
0.70 \\
\end{array}$ & - \\
\hline
\end{tabular}

486 Table 2. Specific contrasts were performed to compare treatment effects and time effects with 487 respect to head movement rate $(\mathrm{df}=108)$ and the amount of time that predators spent near the 488 experimental area $(\mathrm{df}=138)$. Within the treatment effects, we examined whether the control and 489 noise trials differed on night 1, nights 2-5 (averaged), and nights 6-7 (averaged). Within the time 490 effects, we examined whether there were differences within the control or noise trials on night 1 491 compared to night 2-5 (averaged), nights 2-5 (averaged) compared to nights 6-7 (averaged), night 4921 compared to night 6-7 (averaged), and night 2 compared to night 5. Contrasts were considered 493 significant if they are less than the Bonferroni corrected $\mathrm{p}$-value (18 contrasts; $\mathrm{p}<0.0028)$.

\begin{tabular}{|l|l|l|c|c|}
\hline & & & $\begin{array}{c}\text { A: Head Movement } \\
\text { Rate }\end{array}$ & \\
\hline Treatment & & & & \\
effects & & & & \\
\hline & Night 1 & Control vs. Medium & $0.14(0.89)$ & $0.86(0.39)$ \\
\hline
\end{tabular}




\begin{tabular}{|c|c|c|c|c|}
\hline & & Noise & & \\
\hline & Night 1 & $\begin{array}{c}\text { Control vs. Loud } \\
\text { Noise }\end{array}$ & $0.39(0.70)$ & $0.58(0.56)$ \\
\hline & $\begin{array}{c}\text { Nights 2- } \\
5 \\
\end{array}$ & $\begin{array}{c}\text { Control vs. Medium } \\
\text { Noise } \\
\end{array}$ & $2.82(0.0056)$ & $\begin{array}{c}4.62 \\
(<0.0001)\end{array}$ \\
\hline & $\begin{array}{c}\text { Nights 2- } \\
5 \\
\end{array}$ & $\begin{array}{c}\text { Control vs. Loud } \\
\text { Noise } \\
\end{array}$ & $1.66(0.099)$ & $\begin{array}{c}3.61 \\
(0.0004) \\
\end{array}$ \\
\hline & $\begin{array}{c}\text { Nights 6- } \\
7\end{array}$ & $\begin{array}{c}\text { Control vs. Medium } \\
\text { Noise }\end{array}$ & $0.93(0.35)$ & $0.47(0.64)$ \\
\hline & $\begin{array}{c}\text { Nights 6- } \\
7 \\
\end{array}$ & $\begin{array}{c}\text { Control vs. Loud } \\
\text { Noise }\end{array}$ & $0.60(0.55)$ & $1.45(0.15)$ \\
\hline \multicolumn{5}{|l|}{ Time effects } \\
\hline & Control & $\begin{array}{l}\text { Night } 1 \text { vs. Night 2- } \\
5 \\
\end{array}$ & $1.19(0.23)$ & $2.4(0.018)$ \\
\hline & Medium & $\begin{array}{c}\text { Night } 1 \text { vs. Night 2- } \\
5 \\
\end{array}$ & $0.53(0.60)$ & $1.66(0.10)$ \\
\hline & Loud & $\begin{array}{c}\text { Night } 1 \text { vs. Night 2- } \\
5\end{array}$ & $0.56(0.58)$ & $0.89(0.38)$ \\
\hline & Control & $\begin{array}{c}\text { Night } 2-5 \text { vs. Night } \\
\text { 6-7 }\end{array}$ & $0.02(0.98)$ & $1.92(0.057)$ \\
\hline & Medium & $\begin{array}{c}\text { Night } 2-5 \text { vs. Night } \\
\text { 6-7 } \\
\end{array}$ & $1.44(0.15)$ & $1.15(0.25)$ \\
\hline & Loud & $\begin{array}{c}\text { Night } 2-5 \text { vs. Night } \\
6-7 \\
\end{array}$ & $0.54(0.59)$ & $\begin{array}{c}2.98 \\
(0.0034) \\
\end{array}$ \\
\hline & Control & $\begin{array}{c}\text { Night } 1 \text { vs. Night 6- } \\
7 \\
7\end{array}$ & $1.04(0.30)$ & $0.71(0.48)$ \\
\hline & Medium & $\begin{array}{c}\text { Night } 1 \text { vs. Night 6- } \\
7\end{array}$ & $0.53(0.60)$ & $0.65(0.51)$ \\
\hline & Loud & $\begin{array}{c}\text { Night } 1 \text { vs. Night 6- } \\
7\end{array}$ & $0.90(0.37)$ & $1.40(0.16)$ \\
\hline & Control & Night 2 vs. Night 5 & $0.74(0.46)$ & $0.12(0.91)$ \\
\hline & Medium & Night 2 vs. Night 5 & $0.15(0.88)$ & $1.33(0.19)$ \\
\hline & Loud & Night 2 vs. Night 5 & $0.39(0.70)$ & $0.07(0.94)$ \\
\hline
\end{tabular}


494 Figure 1.

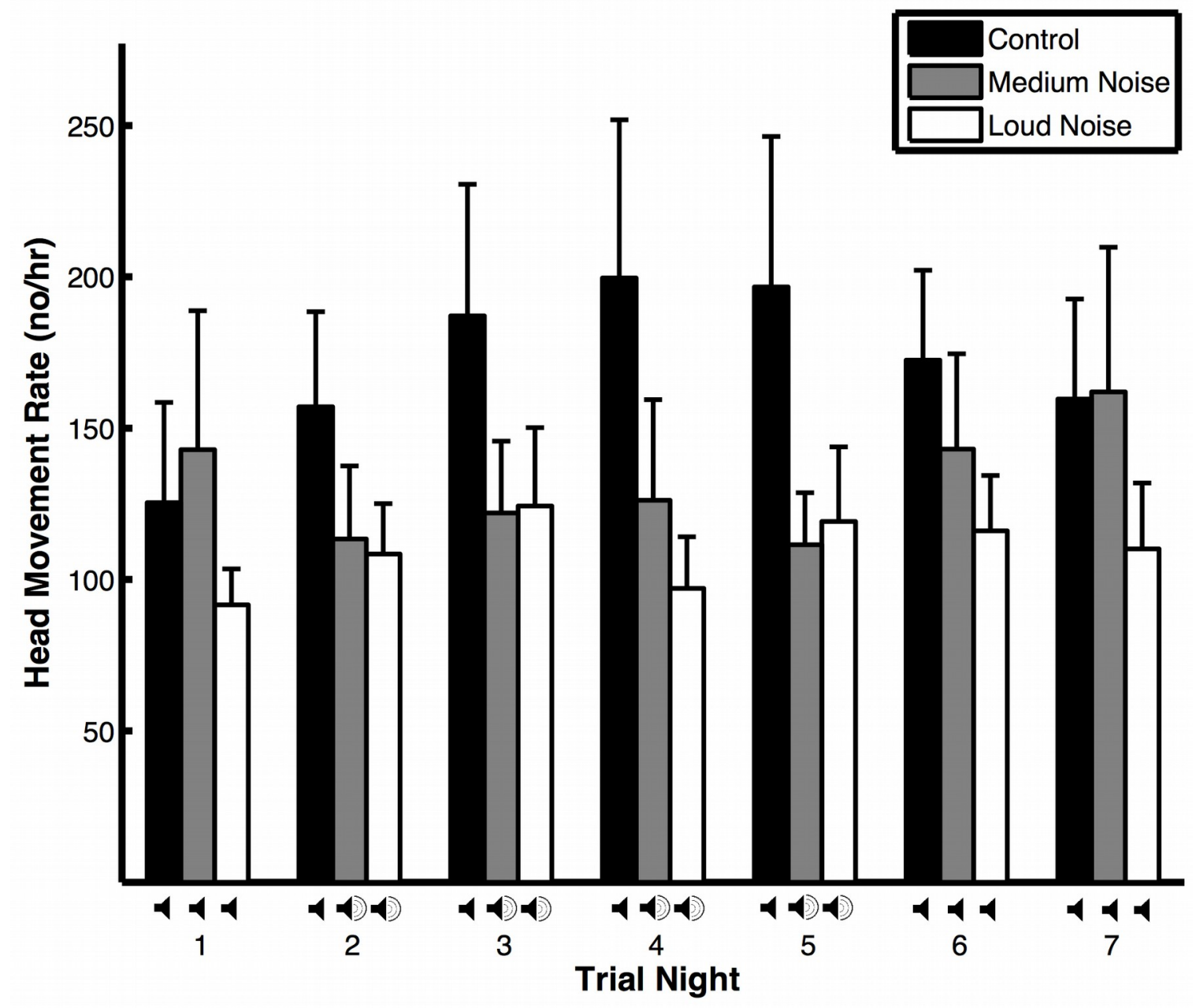


495 Figure 2. 


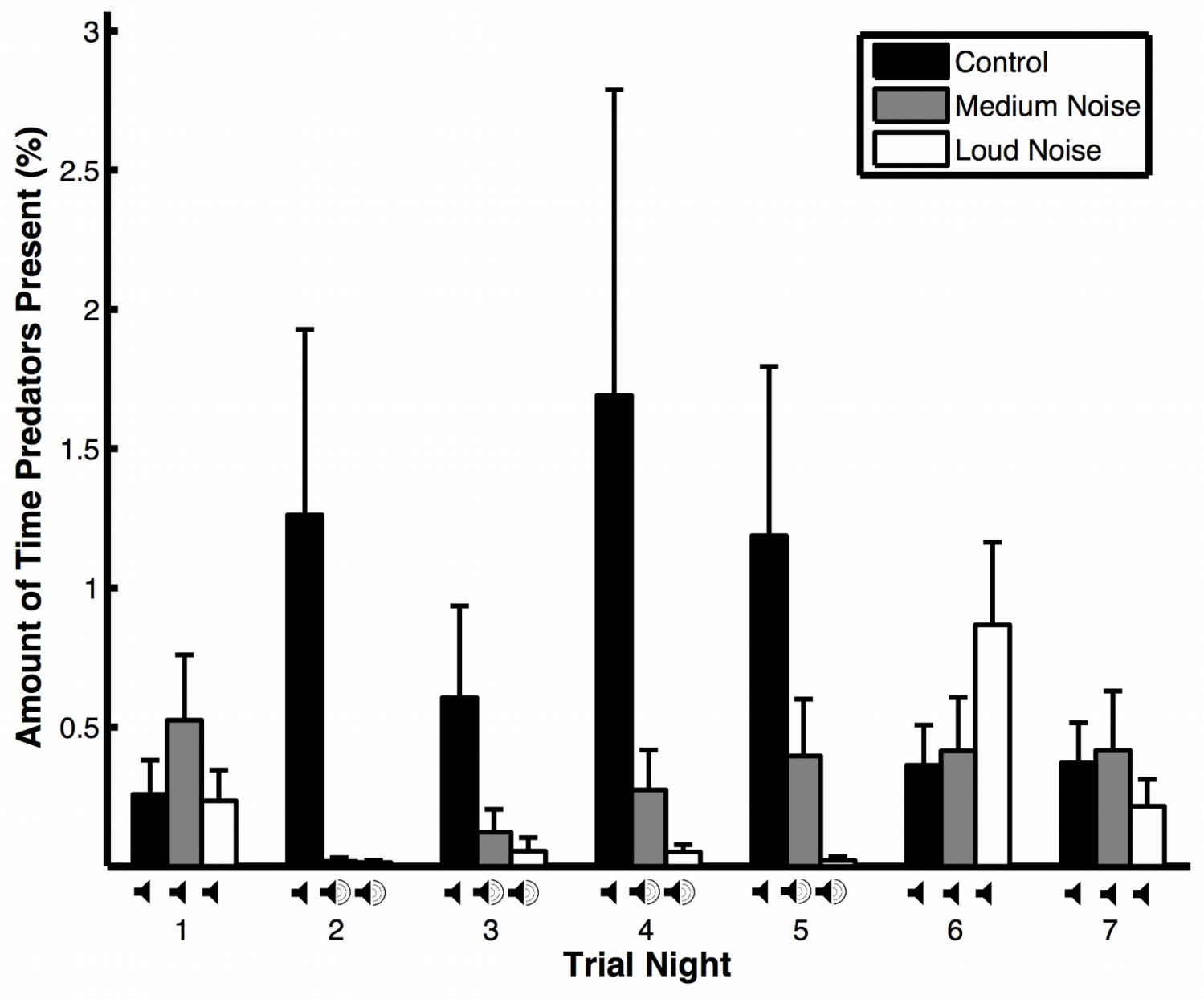

